\title{
Evaluating gaze-driven power wheelchair with navigation support for persons with disabilities
}

\author{
Erik Wästlund, PhD; ${ }^{1 *}$ Kay Sponseller, MSc; ${ }^{2}$ Ola Pettersson, PhD; ${ }^{3}$ Anders Bared, BSc ${ }^{4}$ \\ ${ }^{1}$ Department of Psychology, Karlstad University, Karlstad, Sweden; ${ }^{2}$ Adult Habilitation Center, Landstinget $i$ Värmland, \\ Sweden; ${ }^{3}$ Embint Technology, Örebro, Sweden; ${ }^{4}$ Aurena Laboratories AB, Karlstad, Sweden
}

\begin{abstract}
This article describes a novel add-on for powered wheelchairs that is composed of a gaze-driven control system and a navigation support system. The add-on was tested by three users. All of the users were individuals with severe disabilities and no possibility of moving independently. The system is an add-on to a standard power wheelchair and can be customized for different levels of support according to the cognitive level, motor control, perceptual skills, and specific needs of the user. The primary aim of this study was to test the functionality and safety of the system in the user's home environment. The secondary aim was to evaluate whether access to a gaze-driven powered wheelchair with navigation support is perceived as meaningful in terms of independence and participation. The results show that the system has the potential to provide safe, independent indoor mobility and that the users perceive doing so as fun, meaningful, and a way to reduce dependency on others. Independent mobility has numerous benefits in addition to psychological and emotional well-being. By observing users' actions, caregivers and healthcare professionals can assess the individual's capabilities, which was not previously possible. Rehabilitation can be better adapted to the individual's specific needs, and driving a wheelchair independently can be a valuable, motivating training tool.
\end{abstract}

Key words: assistive devices, assistive robotics, assistive technology, cognitive impairment, disabled persons, eye movement, eye-tracking, gaze control, intelligent wheelchair, navigation support, neurological disorders, path-following, physical impairment, powered wheelchair, rehabilitation, smart wheelchair, user experience, user involvement.

\section{INTRODUCTION}

Individuals with severe disabilities, including combinations of physical, cognitive, communicative, and perceptual impairments, have little or no opportunity to express their own wishes, make choices, or move independently. This user group, such as individuals with severe developmental disabilities, acquired brain injuries, and other neurological impairments, depends totally on others for assistance with all forms of mobility. It is difficult or impossible to clinically evaluate cognitive and perceptual capabilities in individuals who lack voluntary motor control and have severe limitations in terms of expressive communication [1]. There is a risk of misguided expectations and inappropriate habilitation and/or rehabilitation methods; this can result in suboptimal levels of autonomy and independence, which are important factors for a good quality of life [2-3]. Improvements in mobility, pain and discomfort, and quality of life have been shown when people with severe physically disabilities have been provided with an appropriate electric-powered indoor and outdoor chair [3].

\footnotetext{
Abbreviation: ALP = accelerated learning program.

*Address all correspondence to Erik Wästlund, PhD; Department of Psychology, Karlstad University, 65188 Karlstad, Sweden; +46-738359134. Email: erikwast@kau.se http://dx.doi.org/10.1682/JRRD.2014.10.0228
} 
Some of these individuals might benefit from adaptive switches if they cannot control their powered wheelchair with a standard joystick; examples include button control, head control, breath control, and speech control [4-5]. Although a number of studies have applied eyetracking, or gaze-driven, control, only a few have focused on eye-tracking for wheelchair maneuvering $[4,6]$. None of these research systems have been designed in such a way that makes it possible for our intended user group, with limitations in terms of motor control and cognitive functioning, to maneuver the systems. All of the previous systems have demanded a level of understanding and abstract thinking, often in addition to some degree of motor control.

A few systems for gaze-driven control of powered wheelchairs are commercially available [5]. These systems require users to have the cognitive and perceptual capabilities needed to evaluate and react to the environment and voluntary motor control to use two different switches and/or interfaces. ${ }^{*}$ The Rolltalk system requires two voluntary motor actions — one to control a dead man's safety switch and one for gaze-driven control. The cognitive demands are also relatively high with the Rolltalk system because it requires users to shift their focus and have a higher level of abstract understanding and perceptual skills; they need to gaze down to control the wheelchair and gaze up to analyze the environment. The EyeGo system (EyeGo AB; Karlstad, Sweden) is designed to be more intuitive and enable independent mobility for users with severe cognitive impairments. It can be operated using only voluntary control of eye movements. Thus, even though the Rolltalk and EyeGo systems can be fitted on the same wheelchair, their intended user groups are not the same.

A smart wheelchair is a powered wheelchair that has additional functionality [7], such as obstacle detection, line-following, wall-following, docking, and door passage. Many new systems are currently being developed for powered wheelchairs [2,8-9]. To date, testing with the intended user group has been limited and conducted in laboratory settings. Although a few commercially available systems have a line-following function for powered wheelchairs, most have both technical and practical limitations. They are often designed for a specific manufac-

\footnotetext{
*For example, Rolltalk system (Abilia AB; Sollentuna, Sweden): http://www.rolltalk.com/userfiles/46188/Freedom of speech.pdf
}

turer, which limits the possible variety of wheelchairs and adaptations [5]. ${ }^{\dagger}$ The number of people who could benefit from a smart wheelchair is large and growing [10-11].

Clinical experience with existing systems has shown that using systems with simple on-off functionality in order to move freely and safely in a secure environment leads to many positive developments in people with cognitive disabilities [12-13]. This occurs in several different areas, including body and environment awareness, social interaction, communication, and concentration. The ability to move and explore independently is motivating and facilitates learning. Many individuals develop skills for increasingly complex tasks, such as controlling the direction of a wheelchair with increasing levels of independence. By observing the individual's actions when driving independently, families and staff can obtain invaluable information about the individual's skills, interests, and personality. Studies have shown that, among individuals with severe or profound developmental disabilities, the opportunity to make choices in a daily context can reduce inappropriate behavior, increase appropriate behavior, and help identify individual preferences and reinforce stimuli [14].

\section{EyeGo System}

We have previously developed a prototype for gazedriven control of powered wheelchairs or other moving platforms. This system consists of an interface for gazecontrol, a navigation support system that detects and reacts to reflective tape for safe maneuvering, and a junction box that connects to the wheelchair. The development of that system and results from laboratory tests with individuals from the intended user group are described elsewhere [15]. The system can be adapted and fitted to the user's current equipment. Thus, it is an add-on to a standard power wheelchair, which creates a smart wheelchair that can be customized for different levels of support according to the cognitive level, motor control, perceptual skills, and specific needs of the intended user. Individuals with severe and/or multiple disabilities can use the support system to safely steer an electric wheelchair in a controlled indoor environment using just their eye movements. The support system's first safety function is tape avoidance, which can be adapted to the individual's needs. The second function

\footnotetext{
${ }^{\dagger}$ For example, Smart Wheelchair and Smart Box (Smile Rehab Ltd; Berkshire, United Kingdom): http://www.smilerehab.com/smartwheelchair.php
} 
is problem-solving to reduce stress and cognitive demand for the user. Specifically, when the sensors identify the tape, the wheelchair automatically backs and turns away from the tape. Therefore, if a user opts to continue driving straight ahead upon reaching a boundary tape, the wheelchair will turn and continue in a safe direction. To ensure user safety, we conducted a risk analysis based on the recommendations highlighted in Bates et al. [16], which contains reviews of all previous gaze-drive mobility systems. Our priority has been to develop and test a system that fills users' basic needs to move safely in their own home and can be economically feasible in the near future. Individuals belonging to the intended user group have been involved in the entire development process.

The system consists of three components: a gazedriven user interface, an intelligent junction box, and a navigation support system. These components are described briefly next.

\section{Gaze-Driven User Interface}

In order for the user to be able to steer and control the powered wheelchair with eye movements, an image of the room is shown on the computer screen. A small camera provides this image. Therefore, the user interface essentially comprises a live image of the surroundings in front of the wheelchair, upon which directional arrows are superimposed. In order to reduce the demands on gaze precision, the directional arrows are positioned in the center of a larger active area. The function of the arrow is to show the direction and to draw the user's attention to the center of the active area. When the user focuses within a particular directional area, the arrow is illuminated with the surrounding part of the active area and a signal that corresponds to a joystick command is sent to the wheelchair. The live image with the superimposed directional arrows provides an intuitive and easily understandable means of steering the wheelchair or platform. In order to facilitate the varying capabilities of the users, there are three options for level of control in the user interface; these options allow users to direct the wheelchair in six directions, four directions, or one direction (the single direction option requires the support system). Figure 1 shows the user interface with the fourdirection option selected. Here, the user focuses on the arrow pointing forward. Furthermore, the user interface settings include options to take into account the presence of microsaccades (small, normal, involuntary eye movements). The Frozen Gaze function stops the wheelchair

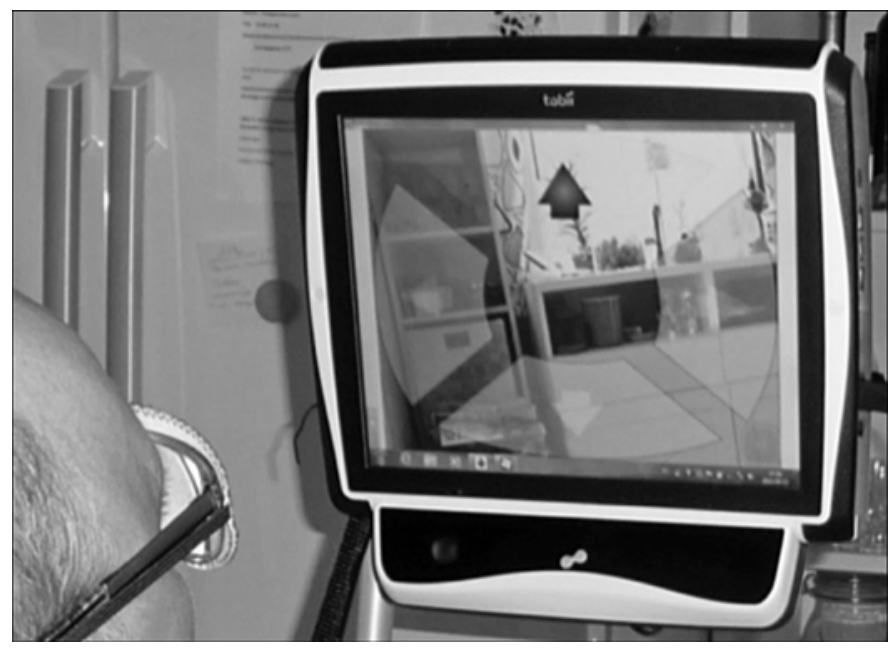

Figure 1.

User interface with live image of surroundings and four directional arrows. Note that forward arrow is activated.

when no saccades are detected within a set time. This function avoids the risk of an involuntary fixated stare (or eye-tracking malfunction) being interpreted as a voluntary command and also enables users to stop the movement of the wheelchair at any point in time by simply closing their eyes. The Delay function can be adjusted to filter out fixations due to involuntary head and eye movements.

\section{Intelligent Junction Box}

The user interface is connected to the junction box, which acquires direction commands from the user and sensor information from the optional support system. A microcontroller makes decisions in real-time and sends direction commands to the powered wheelchair through the joystick port. The wheelchair recognizes the junction box as a regular joystick. The junction box is compatible with all wheelchair systems that utilize the R-net system (PG Drives Technology; Anaheim, California), such as Invacare (Elyria, Ohio) and Permobil (Lebanon, Tennessee), and can also be used with any wheelchair that can be fitted with simple 1- to 4-button input devices.

\section{Navigation Support System}

The support system is an optical line navigation system. When installed, the power wheelchair detects and avoids reflective tape attached to the floor (Figure 2). When a line is detected, the EyeGo system briefly takes control and aids the user by maneuvering the wheelchair 
JRRD, Volume 52, Number 7, 2015

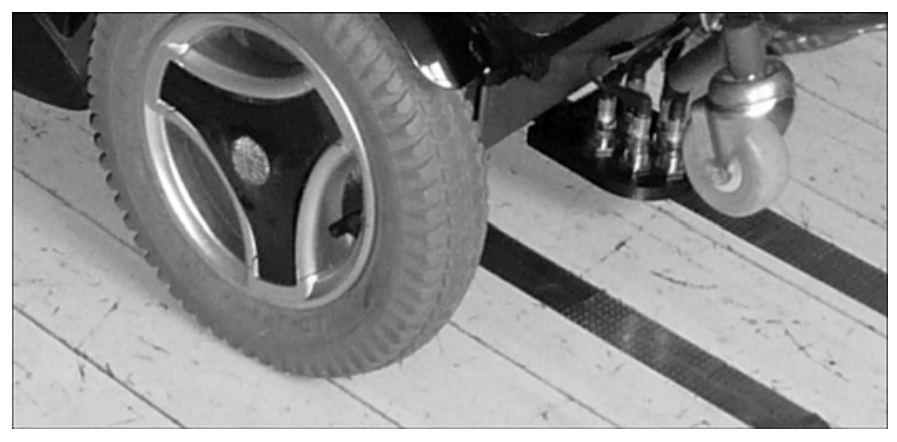

Figure 2.

Navigation support system mounted on powered wheelchair.

into a possible route forward. This reduces the cognitive perceptual demands. The advantage of avoiding the tape instead of following it (as line-following robots do) is that it allows for greater flexibility. In its most supportive setup, the wheelchair follows a designated pathway (Figure 3(a)). The combination of path-following and the one-direction user interface option means that even individuals with severe cognitive and perceptual impairments can drive the wheelchair independently and safely. All the user has to do is to look at the screen and the wheelchair will drive along the designated path. The Boundary Drive function enables users with a higher level of cognitive functioning to steer the chair with the four-direction interface option in any direction, but only within a predefined area. The Boundary Drive function can also be combined with path-following so that the boundary is made into a path in more restricted areas such as hallways or door openings (Figure 3(b)). During such a setup, the user is free to drive in any direction in the open space but will only have to steer straight ahead to navigate through areas such as hallways and door openings. Finally, high-functioning users who are able to drive the wheelchair without any support can still benefit from assistance during difficult passages such as door openings (Figure 3(c)).

\section{METHODS}

This study was approved and partially funded by the Research and Development Department of the County Council of Värmland responsible for healthcare services. The Regional Ethical Review Board of Uppsala, Sweden (registration number 2010/377) granted ethical approval (a)

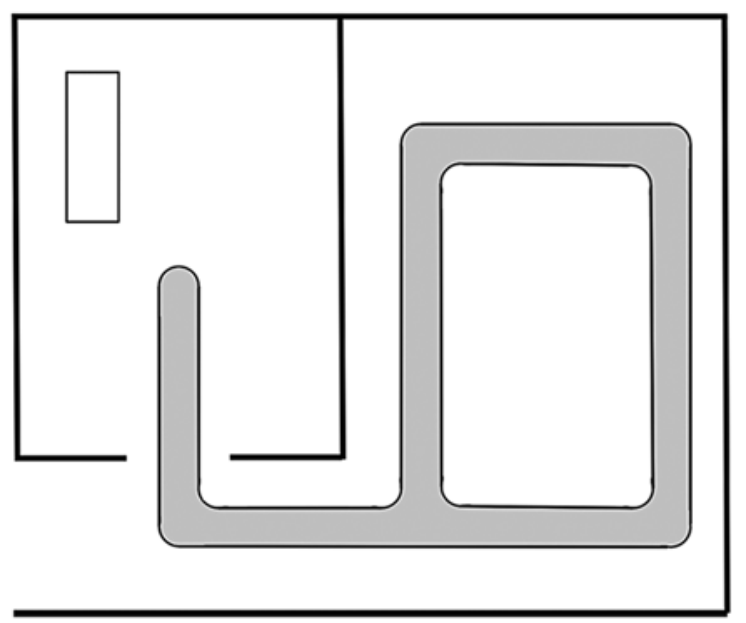

(b)

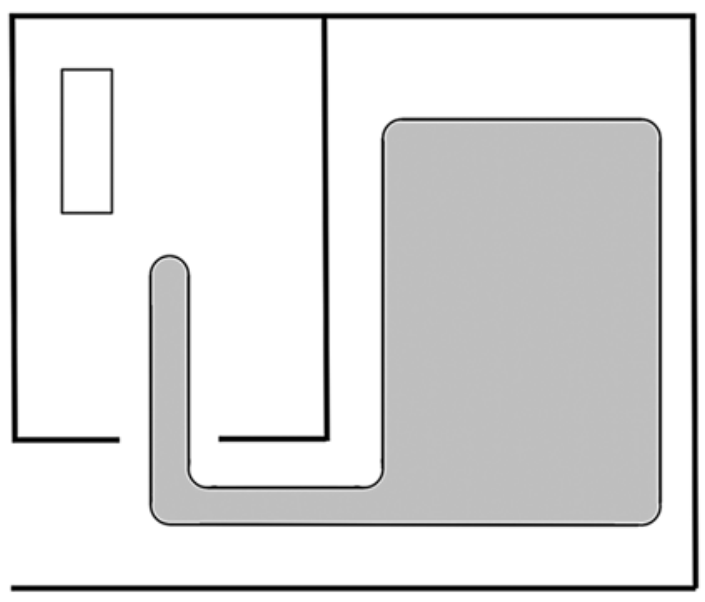

(c)

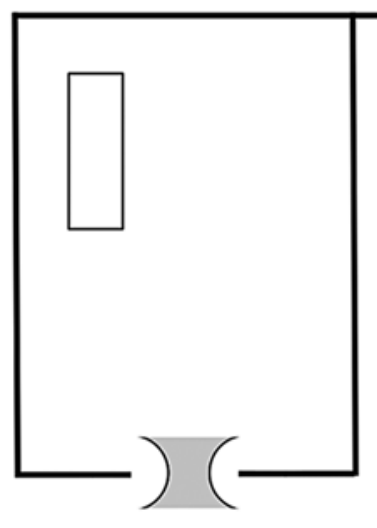

Figure 3.

Three examples of different levels of support offered by EyeGo system (boundaries of gray areas correspond with placement of reflective tape). (a) Path-following. (b) Boundary drive combined with path-following. (c) Free drive combined with assistance in doorway. 
for the study. Furthermore, each system has been constructed and registered according to the Swedish regulations for a special adapted product.

The objective of the study was to answer the following research questions:

1. Can the EyeGo system be customized to functionally meet varied needs depending on the user's cognitive level, perceptual capacity, and control of eye movements?

2. Is the EyeGo system safe and easy to understand and manage, both for users and caregivers?

3. Does using the gaze-driven power wheelchair increase the level of independent movement, communication, and participation in daily activities for individuals with severe impairments?

We used a qualitative case study method. The data collected concern the users' and their caregivers' needs, ideas, responses to the system's functionality, and significance for the user. Written consent forms were collected from all participants.

\section{Study Participants}

Three adults with severe motor impairment and two caregivers for each user were recruited. Study participants were recruited and chosen by the primary investigator's colleagues, physiotherapists, and occupational therapists working with the intended user group. All participants lived in their own homes and received extensive personal assistance. The users were considered representative of the spectrum of needs of the intended user group. The three users had different diagnoses: multiple sclerosis, Duchenne muscular dystrophy, and locked-in syndrome.

The participants' control of their voluntary movement was extremely limited, energy-demanding, and nonfunctional. All users required extensive adapted seating and head support. Communication, cognitive, and perceptual skill levels varied. All users were totally dependent on caregivers for all position changes, mobility, nursing care, and activities of daily living. Two of the study participants had previously been able to control their powered wheelchairs but had lost that capacity as their impairments progressed. Neither of them had driven independently for at least 3 yr because currently available control systems do not meet their needs. The number of participants was limited to three in order to minimize risks in this development phase. Gaze-driven control was evaluated as the only possibility for independent control for all three participants.

There were two inclusion criteria. First, users had to be able to understand verbal information about the wheelchair's functions and have two caregivers who knew the participant well. Second, the participants' caregivers had to have their employer's permission to participate in the study. Assessment of whether the inclusion criteria were met was made by the primary clinical investigator in consultation with the participant's network (family, caregivers, and habilitation and/or rehabilitation professionals).

Exclusion criteria were individuals who had severe cognitive impairments, for which the learning process is often long and highly dependent on a predictable and consistent response from staff and adaptive equipment.

\section{Phase 1}

Each of the representatives of the user group, together with their caregivers, were informed and instructed in the functions of the gaze-driven interface and support system. Each caregiver then test-drove the system, both with gazedriven control and caregiver operation mode, in a controlled indoor environment. This was followed by the user test. Each participant tested all of the support system's functions, i.e., free navigation, path-following, and Boundary Drive function.

User training continued in a controlled clinical setting. The primary clinical investigator, in consultation with the participant's network, decided which functional control mode was appropriate. Adaptations concerning seating and eye-tracker positions were also adjusted as needed. Responsible caregivers participated in each test session and gradually took responsibility for training sessions in the controlled clinical setting under the supervision of the clinical investigators. In two cases, the EyeGo system was mounted on the user's own powered wheelchair, and in one case, it was mounted on a borrowed wheelchair. The clinical investigation team, the users, and their caregivers evaluated when the training situation was moved to the home environment. This decision was based on the capacity of the participants and their caregivers to safely manage the system. Thus, this was a collaborative decision based on the confidence of the responsible caregiver, research team, and user. The structure, duration, and total number of training situations were adapted to the individual needs of each user. 
Before the study, each user, together with his or her caregivers, provided background information with a brief description of the individual's relevant limitations and skills in the areas of communication, motor control, mobility, perception, and health issues.

An interview guide and observation protocol developed by the clinical investigators was used after the test and training passes in the laboratory situation. The observation protocol was inspired by Nilsson and Eklund [17]. The primary clinical investigator carried out and summarized the interviews. Video recording of training sessions was often performed in the laboratory setting. All study participants (users and caregivers) were interviewed about the system's functions, their experiences, and possible problems and suggestions for improvements.

\section{Phase 2}

The users' caregivers were in charge of testing in the home environment. Before the testing, the investigation team evaluated the home environment, applied necessary taped boundaries for two of the users, and ensured the caregivers' capability. Telephone contact from study participants was encouraged, and they were contacted periodically for the purpose of follow-up, problem-solving, and support. All contact was documented.

Standardized forms were used to describe the participant's capabilities in the area of mobility and communication, both before and after the home test period. These templates are inspired by Brandt et al. [18]. Caregivers were also asked to fill in the observation protocol each time they test-drove the system. This was completed with varying degrees of vigilance, and some of the written material was misplaced by one of the caregivers. A summarizing interview was conducted with each participant. All written documentation was presented to and approved by the study participants. As a safety precaution, every test for all participants was conducted under the supervision of a responsible caregiver with a remote stop control.

\section{RESULTS}

Can EyeGo System be Customized to Functionally Meet Varying Needs Depending on User's Cognitive Level, Perceptual Capacity, and Control of Eye Movements?

All users initially tested a variety of interfaces and levels of support. The interface design and level of support was then chosen for each user. Two of the users also needed the navigation support system with varying degrees of freedom of movement. Figure 4 shows an example of a user testing the navigation support system in his home. Table $\mathbf{1}$ includes information on the number of tests and the environment, the interface design, and the level of support for each user. All three users were able to independently control and maneuver a powered wheelchair using the EyeGo system with gaze-control. None of the users had or have the ability to move independently with their own present wheelchairs.

\section{Is EyeGo System Safe and Easy to Understand and Manage for User and Assisting Caregivers?}

All caregivers responded that the verbal and written instructions were easy to understand. The software was perceived as easy to learn. Depending on the caregivers' own interest and experience with technical devices, the users needed to operate the system independently without support between two and six times before feeling secure. During initial testing of the system, incidents occurred in which the wheelchair crossed the taped boundaries; consequently, a remote stop control was used at all times throughout the study. Adverse effects were documented

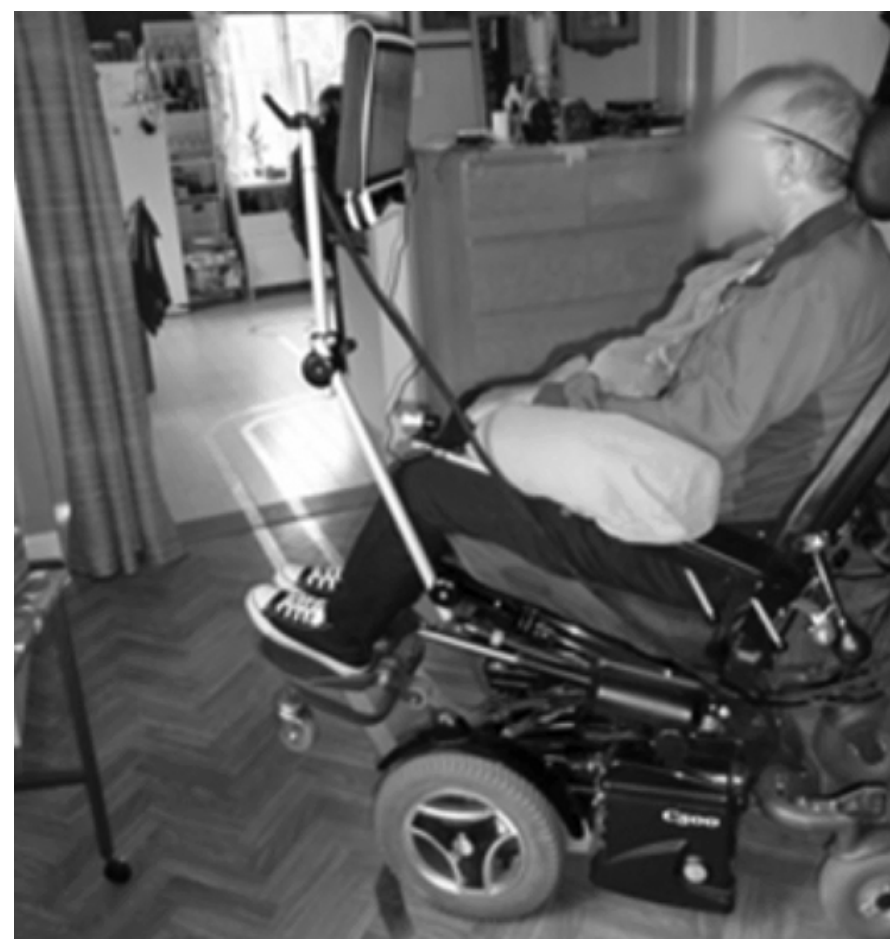

Figure 4.

Study participant (male, age: $61 \mathrm{yr}$ ) testing system in his home. 
Table 1.

Study participants: number of tests, user interface, and level of support.

\begin{tabular}{|c|c|c|c|}
\hline $\begin{array}{c}\text { User (Sex \& } \\
\text { Age, yr) }\end{array}$ & $\begin{array}{l}\text { Test Environment } \\
\text { (No. of Tests) }\end{array}$ & GUI & Level of Support \\
\hline Female (70) & Laboratory (4), home (1). & $\begin{array}{l}\text { Four directional transparent fields over } \\
\text { front-view video of environment. }\end{array}$ & $\begin{array}{l}\text { Infrared sensor support system with } \\
\text { combination of path-following and } \\
\text { boundary drive. }\end{array}$ \\
\hline Male (61) & Laboratory (7), home (80). & $\begin{array}{l}\text { Initial test: Single switch (on/off) } \\
\text { function. Home test: Four direc- } \\
\text { tional transparent fields over front- } \\
\text { view video of environment. }\end{array}$ & $\begin{array}{l}\text { Support system with combination of } \\
\text { path-following and boundary drive. }\end{array}$ \\
\hline Male (35) & $\begin{array}{l}\text { Laboratory (4), home (7), sports } \\
\text { hall (2), grocery store (1). }\end{array}$ & $\begin{array}{l}\text { Initial test: Four directional transpar- } \\
\text { ent fields. Home test: Six direc- } \\
\text { tional transparent fields over front- } \\
\text { view video of environment. }\end{array}$ & Free navigation (no support system). \\
\hline
\end{tabular}

and analyzed, and the EyeGo system was developed to ensure safety. Two major factors caused boundary crossing. The first factor was system architecture. Initially, the robotics software was running in the eye-tracker-enabled personal computer, resulting in loss of input and output signals during excessive central processing unit loads, which essentially made the system "blind." In response, the robotics software was moved to a microcontroller fitted into the EyeGo junction box. The second factor was related to varying wheelchair weight and deceleration speed, which necessitated software adaptation. Caregivers evaluated the most difficult part of starting up the system to be the mechanical placement of the eye-tracker in order to obtain an optimal calibration. Daily adaptations to seating and head support needs were also critical for optional function and comfort.

\section{Does Level of Independent Movement, Communication, and Participation in Daily Activities Increase for Individuals with Severe Impairments by Using Gaze-Driven Power Wheelchair?}

In order to assess the users' expectations and how well they were met, as well as the effect that the EyeGo system had on their ability to move, we assessed some of the items from the standardized forms. The results show that the EyeGo system surpassed the expectations of the study participants (Table 2).

The change in level of mobility capacity was dramatic for all three users, from totally dependent to independent indoors (in two cases with support). Figure 5 shows one user driving independently and making his own choices.
One participant (female, age: $70 \mathrm{yr}$ ) chose to discontinue the study due to health deterioration before the extended test in her home environment. An improved level of communication was achieved for the user who otherwise has no effective expressive communication. A higher level of participation with increased independence and freedom to make choices was apparent for the two users who completed phase 2. Table 3 provides a description of mobility capability with and without the tested system and each of the user's subjective comments.

\section{DISCUSSION}

The primary aim of this study was to test functionality and safety of the system in the user's home environment. The secondary aim was to evaluate whether access to a gaze-driven powered wheelchair with navigation support is perceived as a meaningful improvement in independence and participation. The results show that, for the intended user group, the system has the potential to provide safe, independent indoor mobility and that doing so is perceived as fun and meaningful and reduces dependency on others.

Each user has contributed in many ways to the understanding of his or her needs and the development of the system. It is not possible for individuals without disabilities to simulate or prioritize their unique needs. The gazedriven user interface was evaluated by all users as being intuitive and easy and quick to learn. This is attributed to 
Table 2.

Some study participant responses to items on standardized form.

\begin{tabular}{|c|c|c|c|}
\hline \multirow{2}{*}{ Question } & \multicolumn{3}{|c|}{ User (Sex \& Age, yr) } \\
\hline & Female (70) & Male (61) & Male (35) \\
\hline $\begin{array}{l}\text { What expectations do you have for the } \\
\text { EyeGo system? (Response scale: } \\
\text { open) }\end{array}$ & $\begin{array}{l}\text { "I can drive myself when I } \\
\text { want to watch TV or to } \\
\text { the kitchen when I'm } \\
\text { hungry. It would be nice } \\
\text { to just look around my } \\
\text { apartment.” }\end{array}$ & $\begin{array}{l}\text { Wife: "Primarily as a com- } \\
\text { munications aid. He can } \\
\text { move away from us if he } \\
\text { wants to be alone or if he } \\
\text { decides to do something } \\
\text { else." }\end{array}$ & $\begin{array}{l}\text { "I can go where I want to by } \\
\text { myself. It has been a long } \\
\text { time, almost three years, } \\
\text { since I could drive my } \\
\text { wheelchair myself." }\end{array}$ \\
\hline $\begin{array}{l}\text { How have your expectations been ful- } \\
\text { filled? (Response scale: 5-point scale } \\
\text { from “Much better than I expected” } \\
\text { to "Much less than I expected.”) }\end{array}$ & Did not complete survey & Better than I expected & Better than I expected \\
\hline \multicolumn{4}{|l|}{$\begin{array}{l}\text { How much help do you need from } \\
\text { another person to move between } \\
\text { rooms? (Response scale: 5-point scale } \\
\text { from "No help” to “Total help.”) }\end{array}$} \\
\hline With Own Assistive Aids & Total help & Total help & Total help \\
\hline Using EyeGo System & Did not complete survey & No help/little help & No help \\
\hline Comments & $\begin{array}{l}\text { According to observa- } \\
\text { tions, she drove with lit- } \\
\text { tle help between rooms. }\end{array}$ & $\begin{array}{l}\text { Sometimes in need of a lit- } \\
\text { tle assistance. }\end{array}$ & - \\
\hline $\begin{array}{l}\text { What significance has access to the EyeGo } \\
\text { system had for your ability to participate } \\
\text { in different activities? (Response scale: } \\
\text { 5-point scale from "Great significance” } \\
\text { to "No significance.”) }\end{array}$ & Did not complete survey & Large significance & $\begin{array}{l}\text { Some significance (in a } \\
\text { follow-up interview, user } \\
\text { attributed this to small } \\
\text { size of his apartment) }\end{array}$ \\
\hline
\end{tabular}

the multimodal reinforcing stimuli: visual with directional arrow activation and mobile environmental camera and physical movement of the chair.

The system, as tested in this study with gaze-driven control, fulfilled criteria regarding functionality and safety. Numerous studies have documented the positive benefits of involving intended users in the development process [19]. For the present study and development work, the extensive user testing and feedback has been invaluable. Many factors are critical to successfully matching the system with the user. Caregivers and healthcare professionals are essential for identifying the most suitable design and adaptation needs for each individual user. This regards issues such as the level of support, user interface, seating support, and placement of the eyetracker. A training period with support for both users and caregivers is essential, as is follow-up. The motivation of both the users and caregivers depends on the balance

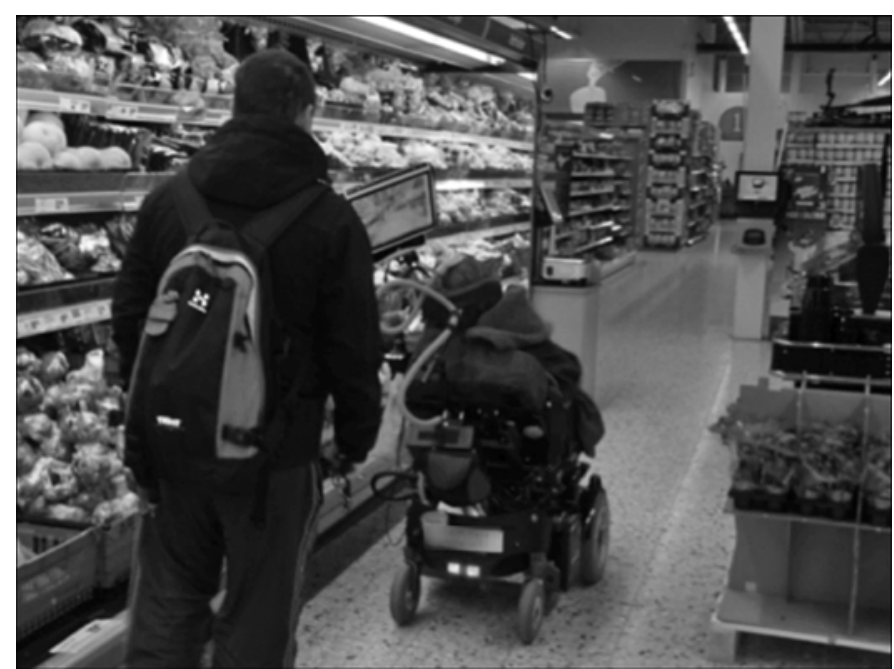

Figure 5.

Study participant (male, age: 35 yr) trying out EyeGo system in grocery store. 
between demands and degree of freedom corresponding with the users' abilities.

All three participants expressed that they would like to continue their involvement in future development work. They also expressed a need and desire for further product developments. The two most important wishes are the ability to change seating position with eye movement and the possibility of driving outdoors. The first request can be solved by the EyeGo system, whereas the second requires developments in eye-tracking technology.

A great deal of consideration was given to the choice of participants in order to achieve a wide variety of users' abilities and needs. However, one obvious limitation to this study is the small number of participants. Because the focus of this study was validation of safety issues, we did not include users with severe cognitive impairments, even though we believe this group would benefit greatly from using the system. Future research must be conducted with a larger population of potential users, prescribers, rehabilitation teams, and caregivers in order to develop specific methods for the prescription assessment; training models; and development of evaluation methods of cognition, communication, and perceptual functioning that uses the ability to execute independent actions as a tool.

Another limitation is that the length of the study and the few participants meant that we have very little data concerning our second aim, which was to evaluate whether access to a gaze-driven powered wheelchair with navigation support

Table 3.

Study participants' mobility capability, participation, and subjective comments.

\begin{tabular}{|c|c|c|c|}
\hline \multirow{2}{*}{ Study } & \multicolumn{3}{|c|}{ User (Sex \& Age, yr) } \\
\hline & Female (70) & Male (61) & Male (35) \\
\hline $\begin{array}{l}\text { Mobility Capability with Per- } \\
\text { sonal Adaptive Equipment } \\
\text { and Caregiver Support }\end{array}$ & $\begin{array}{l}\text { Totally dependent on physical } \\
\text { assistance for all position } \\
\text { changes, transfers, and } \\
\text { indoor and outdoor mobility } \\
\text { in manual wheelchair. Ceil- } \\
\text { ing lift used for transfers. }\end{array}$ & $\begin{array}{l}\text { Totally dependent on others’ } \\
\text { initiative, choices, and phys- } \\
\text { ical assistance for all posi- } \\
\text { tion changes, transfers, and } \\
\text { indoor and outdoor mobility } \\
\text { in powered wheelchair. }\end{array}$ & $\begin{array}{l}\text { Totally dependent on physical } \\
\text { assistance for all position } \\
\text { changes, transfers, and indoor } \\
\text { and outdoor mobility in pow- } \\
\text { ered wheelchair. Two caregiv- } \\
\text { ers lift manually for transfers. }\end{array}$ \\
\hline $\begin{array}{l}\text { Mobility Capability with } \\
\text { Tested Gaze-Driven EyeGo } \\
\text { System of Powered } \\
\text { Wheelchair }\end{array}$ & $\begin{array}{l}\text { Independent mobility within } \\
\text { boundary drive areas when } \\
\text { secure in laboratory environ- } \\
\text { ment. Many stops and starts. } \\
\text { Direction changes made } \\
\text { slowly (not fully automatic). }\end{array}$ & $\begin{array}{l}\text { Independent mobility with } \\
\text { path-following and limited } \\
\text { boundary drive areas. Many } \\
\text { stops and starts because of } \\
\text { erratic eye-movements. Ini- } \\
\text { tially primarily controlled } \\
\text { stop-go on given path. Has } \\
\text { started to anticipate turns and } \\
\text { voluntarily make direction } \\
\text { changes and choices about } \\
\text { where to be. }\end{array}$ & $\begin{array}{l}\text { Independent indoor mobility } \\
\text { with good precision when } \\
\text { there was adequate space. } \\
\text { Drove freely in grocery store } \\
\text { and sports hall. Limited } \\
\text { accessibility in own home } \\
\text { allowed only free movement } \\
\text { between two rooms. }\end{array}$ \\
\hline
\end{tabular}


Table 3.

Study participants’ mobility capability, participation, and subjective comments.

Subjective Evaluation and $\quad$ "Initially strange, scary, and Wife: “Access to the system has Comments

fun. Easy to understand. Not

been very significant. It has tiring because it is fun. Harder at home; it feels like the chair moves more quickly when I get close to my own things. Do not fully trust my own reactions and those of the wheelchair. I would be too nervous to drive myself at home.” strongly contributed to his rehabilitation. He is motivated, more alert, tries to move more, and is happier after he has driven the chair. It stimulates all his senses. Head control, control of eye movements, and stamina have steadily improved.” User confirms that he finds system to be fun and meaningful, and he wants to keep system.
"Easy to understand, drive, and maneuver the wheelchair. Works better than I expected. It is fun to be able to drive myself. I can go where I want to without asking others. If there was more room at home, I would have greater freedom with this system.” is perceived as a meaningful improvement in independence and participation. The standardized forms that we used were not optimal. The most valuable instrument was the open interview questions to both the users and caregivers. The newly developed assessment tool of learning powered mobility use (accelerated learning program [ALP]) and the identified strategies to facilitate learning would provide a valuable tool for future studies [20]. In addition to being a standardized assessment to use in research concerning different control systems such as the EyeGo, the ALP is a pedagogical tool for educating and supporting caregivers. This is essential if the user, independent of cognitive capacity, is to have the necessary conditions to succeed.

\section{CONCLUSIONS}

Many individuals with severe disabilities who are currently totally dependent on others can obtain a higher level of independence with access to gaze-driven control of a powered wheelchair with an appropriate degree of navigation support.

The new opportunity for independent mobility and actions for individuals who are totally dependent on others, some of whom cannot communicate their wishes, has many important benefits. Psychological and emotional well-being improves with the ability to independently choose when and where to move. Independent actions provide a form of communication. By observing an individual's behavior and actions with the wheelchair in different environments and situations, caregivers and healthcare professionals can assess the individual's perceptual and cognitive capabilities, which was previously impossible.
Rehabilitation can be better adapted to the individual's specific needs. Driving a wheelchair independently can be a valuable, motivating training tool for factors such as concentration, spatial orientation, and integration of perceptual stimuli. The interface and level of support can be adapted to both the development and loss of skills.

The EyeGo system is a promising way to provide a user-friendly gaze-driven control and navigation support system for powered wheelchair users to enable a degree of independence for individuals with severe impairments.

\section{ACKNOWLEDGMENTS}

\section{Author Contributions:}

Study concept and design: E. Wästlund, K. Sponseller.

Acquisition, analysis, and interpretation of data: E. Wästlund, K. Sponseller.

Drafting of manuscript: E. Wästlund, K. Sponseller.

Critical revision of manuscript for important intellectual content:

E. Wästlund, K. Sponseller, O. Pettersson, A. Bared.

Obtained funding: E. Wästlund, K. Sponseller, O. Pettersson, A. Bared.

Administrative, technical, or material support: E. Wästlund, K. Sponseller, O. Pettersson, A. Bared.

Financial Disclosures: The system described in the article was developed during a research project conducted in collaboration between Karlstad University, the County Council of Värmland, and Embint Technology. The participating researchers have since then founded the company EyeGo AB, which owns the intellectual property rights, and our ambition is to turn the system described in the article into a commercial product. Neither Permobil AB nor Tobii Technology AB have any stakes in the project, but they have kindly lent equipment (wheelchair and eye tracker).

Funding/Support: This material was based on work supported by the Promobilia Foundation (grant KAU: 2012/82) and the Research and 
Development Department of the County Council of Värmland (grant LIVFOU-105451).

Additional Contributions: The authors would like to especially thank the volunteers who participated in this study for their invaluable feedback. This study would not have been possible without support from the Adult Habilitation Center, Central Service for Assistive Aids, the Research and Development Department of the County Council of Värmland, Karlstad University, Permobil AB, and Tobii Technology AB.

Institutional Review: The Regional Ethical Review Board of Uppsala, Sweden, granted ethical approval for the study (registration number 2010/377). Written consent forms were collected from all participants.

Participant Follow-up: The participants will be notified of the publication of this study.

\section{REFERENCES}

1. Schnakers C, Majerus S, Goldman S, Boly M, Van Eeckhout P, Gay S, Pellas F, Bartsch V, Peigneux P, Moonen G, Laureys S. Cognitive function in the locked-in syndrome. J Neurol. 2008;255(3):323-30. [PMID:18350365]

2. Cowan RE, Fregly BJ, Boninger ML, Chan L, Rodgers MM, Reinkensmeyer DJ. Recent trends in assistive technology for mobility. J Neuroeng Rehabil. 2012;9:20. [PMID:22520500] http://dx.doi.org/10.1186/1743-0003-9-20

3. Davies A, De Souza LH, Frank AO. Changes in the quality of life in severely disabled people following provision of powered indoor/outdoor chairs. Disabil Rehabil. 2003;25(6): 286-90. [PMID:12623619] http://dx.doi.org/10.1080/0963828021000043734

4. Bates R, Daunys G, Villanueva A, Castellina E, Hong G, Istance $\mathrm{H}$, Gale A, Lauruska V, Spakov O, Majaranta P. D2.4: A survey of existing “de-facto” standards and systems of environmental control: IST-2003-511598 [Internet]. Frederiksberg (Denmark): Communication by Gaze Interaction; 2006 [updated 2006 Oct 34]. Available from: http://wiki.cogain.org/images/6/60/COGAIN-D2.4.pdf

5. Urdiales C, Peula Palacios JM, Fdez-Carmona M. Collaborative assistive robot for mobility enhancement (CARMEN): The bare necessities: Assisted wheelchair navigation and beyond. Berlin (Germany): Springer; 2012.

6. Barea R, Boquete L, Bergasa LM, López E, Mazo M. Electro-oculographic guidance of a wheelchair using eye movements codification. Int J Robot Res. 2003;22(7-8):641-52. http://dx.doi.org/10.1177/02783649030227012

7. Simpson RC. Smart wheelchairs: A literature review. J Rehabil Res Dev. 2005;42(4):423-36. [PMID:16320139] http://dx.doi.org/10.1682/JRRD.2004.08.0101

8. Boucher P, Atrash A, Kelouwani S, Honoré W, Nguyen H, Villemure J, Routhier F, Cohen P, Demers L, Forget R, Pineau J. Design and validation of an intelligent wheelchair towards a clinically-functional outcome. J Neuroeng Rehabil. 2013;10(1):58. [PMID:23773851] http://dx.doi.org/10.1186/1743-0003-10-58

9. Zeng Q, Burdet E, Teo CL. Evaluation of a collaborative wheelchair system in cerebral palsy and traumatic brain injury users. Neurorehabil Neural Repair. 2009;23(5):494-504.

[PMID:19074687] http://dx.doi.org/10.1177/1545968308323692

10. Fehr L, Langbein WE, Skaar SB. Adequacy of power wheelchair control interfaces for persons with severe disabilities: A clinical survey. J Rehabil Res Dev. 2000;37(3): 353-60. [PMID:10917267]

11. Wang RH, Korotchenko A, Hurd Clarke L, Mortenson WB, Mihailidis A. Power mobility with collision avoidance for older adults: User, caregiver, and prescriber perspectives. J Rehabil Res Dev. 2013;50(9):1287-1300. [PMID:24458968]

12. Nilsson L. Communication mediated by a powered wheelchair: People with profound cognitive disabilities. Disabil Stud Q. 2011;31(4).

13. Nilsson LM, Nyberg PJ. Driving to learn: A new concept for training children with profound cognitive disabilities in a powered wheelchair. Am J Occup Ther. 2003;57(2):229-33. [PMID:12674317] http://dx.doi.org/10.5014/ajot.57.2.229

14. Cannella HI, O’Reilly MF, Lancioni GE. Choice and preference assessment research with people with severe to profound developmental disabilities: A review of the literature. Res Dev Disabil. 2005;26(1):1-15.

[PMID:15590233] http://dx.doi.org/10.1016/j.ridd.2004.01.006

15. Wästlund E, Sponseller K, Pettersson O. What you see is where you go: Testing a gaze-driven power wheelchair for individuals with severe multiple disabilities. Proceedings of the 2010 Symposium on Eye-Tracking Research and Applications; 2010 Mar 22-24; Austin, TX. New York (NY): Association for Computing Machinery; 2010. p. 133-36.

16. Bates R, Stepankova O, Corno F, Brynildsen OM, Donegan M, Novak P, Krajnik T, Buccholz M, Holmqvist E, Majaranta P. D2.7: Recommendations on safety issues involved in gaze based mobility control: IST-2003-511598 [Internet]. Frederiksberg (Denmark): Communication by Gaze Interaction; 2009 [updated 2009 Apr 14]. Available from: http://wiki.cogain.org/images/1/1d/COGAIN-D2.7.pdf

17. Nilsson LM, Eklund M. Driving to learn: Powered wheelchair training for those with cognitive disabilities. Int $\mathrm{J}$ Ther Rehabil. 2006;13(11):517-27. http://dx.doi.org/10.12968/ijtr.2006.13.11.22466

18. Brandt A, Löfqvist C, Jónsdottir I, Sund T, Salminen AL, Werngren-Elgström M, Iwarsson S. Towards an instrument targeting mobility-related participation: Nordic cross-national reliability. J Rehabil Med. 2008;40(9):766-72.

[PMID:18843431]

http://dx.doi.org/10.2340/16501977-0244 
JRRD, Volume 52, Number 7, 2015

19. Shah SG, Robinson I. Benefits of and barriers to involving users in medical device technology development and evaluation. Int J Technol Assess Health Care. 2007;23(1):131-37. [PMID:17234027] http://dx.doi.org/10.1017/S0266462307051677

20. Nilsson L, Durkin J. Assessment of learning powered mobility use-applying grounded theory to occupational performance. J Rehabil Res Dev. 2014;51(6):963-74.

[PMID:25357100]

http://dx.doi.org/10.1682/JRRD.2013.11.0237

Submitted for publication October 6, 2014. Accepted in revised form June 12, 2015.

This article and any supplementary material should be cited as follows:

Wästlund E, Sponseller K, Pettersson O, Bared A. Evaluating gaze-driven power wheelchair with navigation support for persons with disabilities. J Rehabil Res Dev. 2015;52(7):815-26.

http://dx.doi.org/10.1682/JRRD.2014.10.0228

ORCID: Erik Wästlund, PhD: 0000-0001-8102-8168

\begin{tabular}{|c|c|}
\hline $\begin{array}{l}\text { al suenssions screeneo or: } \\
\text { iThenticate: }\end{array}$ & ef \\
\hline 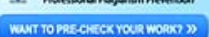 & $\begin{array}{l}\text { CROSSREF.ORG } \\
\text { THE CITATIOH LHKIHG EACKEONE }\end{array}$ \\
\hline
\end{tabular}



828

JRRD, Volume 52, Number 7, 2015 